\title{
Gary Victor, Maudite éducation
}

\section{Emanuela Cacchioli}

\section{(2) OpenEdition}

\section{Journals}

\section{Edizione digitale}

URL: http://journals.openedition.org/studifrancesi/2319

DOI: $10.4000 /$ studifrancesi.2319

ISSN: 2421-5856

\section{Editore}

Rosenberg \& Sellier

\section{Edizione cartacea}

Data di pubblicazione: 1 aprile 2014

Paginazione: 198

ISSN: 0039-2944

\section{Notizia bibliografica digitale}

Emanuela Cacchioli, « Gary Victor, Maudite éducation », Studi Francesi [Online], 172 (LVIII | I) | 2014 online dal 01 avril 2014, consultato il 18 septembre 2020. URL : http://journals.openedition.org/ studifrancesi/2319; DOI : https://doi.org/10.4000/studifrancesi.2319

\section{Questo documento è stato generato automaticamente il 18 settembre 2020.}

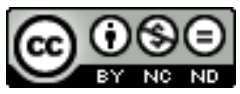

Studi Francesi è distribuita con Licenza Creative Commons Attribuzione - Non commerciale - Non opere derivate 4.0 Internazionale. 


\title{
Gary Victor, Maudite éducation
}

\author{
Emanuela Cacchioli
}

\section{NOTIZIA}

GARY VICTOR, Maudite éducation, Paris, Philippe Rey, 2012, pp. 287.

1 Maudite éducation è un romanzo di iniziazione in cui alcuni dati autobiografici relativi all'adolescenza di Gary Victor si mescolano alla finzione. Il protagonista è Carl Vausier, un ragazzo appartenente ad una famiglia rispettabile di Port-au-Prince che gli impone un'educazione severa, ma che al contempo gli trasmette l'amore per la lettura. Il passaggio dall'infanzia all'adolescenza e successivamente all'età adulta è un'epoca di sofferenza e di solitudine per Carl. L'educazione rigida imposta dal padre non assopisce nel ragazzo il desiderio di conoscere il mondo in tutti i suoi aspetti. La curiosità ed una forte timidezza lo inducono a trovare nella biblioteca il primo luogo di pace e di intimità all'interno dell'abitazione paterna. Quando il suo rifugio viene scoperto, è la notte nei quartieri più poveri di Port-au-Prince a offrirgli una via di fuga dall'austerità familiare. Carl è iniziato alla sessualità dalle prostitute che frequenta in quei luoghi che poco si addicono alla rispettabilità della sua famiglia. Questi incontri, tuttavia, gli consentono, da un lato, di conoscere tutti gli aspetti di una città che altrimenti gli sarebbero preclusi e, dall'altro, di sentire il racconto di storie inverosimili e lontane nel tempo di donne che hanno sofferto a causa della violenza e della brutalità degli uomini o, più in generale, della Storia. Oltre ad alimentare il suo dono innato per l'immaginazione, questi racconti dirigono il giovane Carl alla ricerca della verità. Il suo forte razionalismo si scontra con l'atteggiamento del popolo che assorbe queste vicende inverosimili come se si trattasse di dati acquisiti e scontati. Il protagonista avverte quindi l'esigenza di indagare con estrema lucidità sui fatti misteriosi che gli vengono narrati e trovare una spiegazione razionale per ogni dettaglio apparentemente irreale. Le esperienze vissute confluiscono nei racconti scritti e pubblicati su rivista e nell'attività di giornalista, ma lasciano il segno anche nella sua incapacità di superare la 
timidezza in ambito amoroso e, in particolare, in relazione alla storia tormentata con Cœur qui saigne.

2 Maudite éducation, inserito nella prima selezione di finalisti del premio Médicis 2012, può essere considerato un romanzo di ricerca disperata e dolorosa della verità $\mathrm{e}$ dell'amore. Si tratta anche del racconto di un percorso di iniziazione che un giovane scrittore compie prima di diventare un autore celebre e un giornalista reputato. La sofferenza, il tormento, il senso di colpa accompagnano le varie fasi della vita di questo ragazzo costretto a lottare per conquistarsi uno spazio nella società. Ha particolare rilievo anche il rapporto tra Carl e il padre. Il genitore, nonostante sia motivo di angoscia per il piccolo Carl, diventa una figura di riferimento fondamentale della sua esistenza e un valido supporto per intraprendere la carriera di scrittore. Sullo sfondo la dittatura dei Duvalier, il clima di terrore che hanno instaurato sull'isola e la presenza dei tontons macoutes che contribuisce a mantenere il popolo soggiogato. La denuncia della realtà politica si associa alla descrizione di un quadro sociale disagiato all'interno di un universo dominato dalla bruttezza artificiale del cemento. Non manca, tuttavia, l'evocazione del paesaggio naturale, della bellezza poetica del mare e del cielo. Si tratta di attimi di pace che interrompono il flusso incalzante e denso della narrazione e lo sguardo lucido di Victor sulla società dominata dalla violenza, dalla criminalità e dai tormenti interiori del giovane protagonista. La quotidianità è solitamente descritta nella sua immediatezza, ma è anche filtrata dalla dimensione onirica che spesso si sovrappone alla realtà e confonde i piani dell'enunciazione perché, come afferma Victor: «Quand je plonge dans ma mémoire pour remonter le cours du temps, j'atteins une frontière où il ne m'est plus possible de savoir si les images que je saisis sont celles d'une réalité disparue ou celles d'un temps lointain ou proche» (p. 126). Maudite éducation è un romanzo dallo stile potente, in cui Gary Victor confida al lettore le sue angosce adolescenziali e la fonte della sua inesauribile creatività. 